\title{
Random mutagenesis of a Pseudomonas putida strain capable of acclimating to high-concentration formaldehyde via atmospheric and room temperature plasma(ARTP)
}

Fang Kong ( $\square$ kongfang@ahpu.edu.cn )

Anhui polytechnic university https://orcid.org/0000-0003-2689-5466

\section{Research Article}

Keywords: Pseudomonas putida, Formaldehyde biodegradation, Atmospheric and Room Temperature Plasma, Dual gradient plate, Mutagenesis

Posted Date: January 17th, 2022

DOI: https://doi.org/10.21203/rs.3.rs-1264655/v1

License: (c) (1) This work is licensed under a Creative Commons Attribution 4.0 International License. Read Full License 


\section{Abstract}

Formaldehyde has strong cytotoxicity to organisms and may cause nasopharyngeal cancer and probably leukemia. This study is intended to investigate a highly formaldehyde-resistant utilizer, the Pseudomonas putida W1 strain. Bacterial strain W1 isolated from untreated activated sludge samples collected from heavily formaldehyde- and aniline-contaminated areas was identified using morphological characteristics and molecular techniques. The formaldehyde concentration in the medium decreased with the growth of strain W1. The degradation of formaldehyde concentration depends on the cell number of strain W1. The W1 strain completely consumed $0.5 \mathrm{~g} \mathrm{~L}^{-1}$ of nearly $98 \%$ formaldehyde within $48 \mathrm{~h}$. Atmospheric and room temperature plasma (ARTP) was applied to improve the tolerance to formaldehyde and the genetic stability of $P$. putida. The protocol for rapid mutation was established by different intervals with a fatality rate reaching $99 \%$ and then compared with the dual gradient plate screening method. Growth of the isolated mutant WMZ120-5 strain on formaldehyde was possible up to at least $3 \mathrm{~g} \mathrm{~L}^{-1}$, and survival at up to a concentration of $20 \mathrm{~g} \mathrm{~L}^{-1}$ was possible after stepwise acclimatization. At such high concentrations of formaldehyde, the mutant WMZ120-5 exhibited approximately seven-fold higher expression than the original strain $\mathrm{W} 1$. The characteristics of the mutant after mutagenesis showed good genetic stability after the 10th subculture. Our study demonstrated that strain WMZ120-5 has great potential to utilize formaldehyde at high concentrations in the environment.

\section{Introduction}

Formaldehyde $(\mathrm{H} 2 \mathrm{C}=0)$ is a ubiquitous reactive compound used in industrial processes, agriculture, and pharmaceuticals[1]. Formalin (37\% formaldehyde) is classically used in the fixation of biological specimens, disinfection (e.g., marine aquaculture to control parasitic infection)[2, 3], preservation, and clean water (e.g., pretreatment of portable water by ozonation)[4]. In addition, formaldehyde is a component of materials such as plastics, pesticides and adhesive, from which formaldehyde is released and produces air pollution[5, 6, 7, 8, 9]. The International Agency for Research on Cancer (IARC 2012) has labeled formaldehyde as a category I human carcinogen[10]. The carcinogenic properties and detrimental effects of formaldehyde exposure on growth and reproductive development have been described and summarized extensively[11]. The toxic effects of formaldehyde are attributed to its nonspecific reactivity with biological molecules, i.e., proteins and nucleic acids, and cause genetic damage and mutation in mammalian cells $[12,13,14,15,16]$. Formaldehyde may also induce specific toxicity to biological systems because it is chemically similar to amide and chaotropic agents[17, 18]. Meanwhile, the potent cytotoxin formaldehyde can be formed in nature, i.e. by incomplete combustion of organic materials or in plant biomass and can enter the soil, lake or atmosphere. So it is an environmental pollutant.

In light of these facts, it is urgent to develop a removal strategy that is both low in cost and minimal environmental load. Potential strategies include physical adsorption, chemical catalysis, and biodegradation. Currently, chemical, physical and biological degradation methods have been employed to remove formaldehyde from soil, water and air[19, 20, 21, 22]. However, the method of physically absorbed formaldehyde easily results in saturation and does not truly remove pollution[23]. The major 
disadvantages of chemical oxidation of formaldehyde limit its wide use for high cost in the degradation of organic contaminants. Meanwhile, chemical catalysis adds the risk of introducing secondary pollutants. Formaldehyde biodegradation by microorganisms is an efficient and moderate solution under various conditions[24,25]. Meanwhile, biodegradation does not produce additional chemical hazards in the process. Microbial methods have attracted increasing attention because of their feasibility and rapid decontamination. Numerous microorganisms tolerant to formaldehyde have been isolated and characterized, including Methylobacterium[26], Pseudomonas[27, 28], Rhodococcus[29], Bacillus[30], Aspergillus[31], Paecilomyces[32], microalgae Nannochloropsis oculata[33], Acetobacter [34] and Corynebacterium glutamicum[35]. Among these reported strains, those belonging to Pseudomonas sp. demonstrated formaldehyde tolerance and relatively high degradation rates. For instance, Paecilomyces sp. No. 5 can degrade very high formaldehyde concentrations $\left(20 \mathrm{~g} \mathrm{~L}^{-1}\right)$ but with a relatively low degradation rate $\left(41.6 \mathrm{mg} \mathrm{L}^{-1} \mathrm{~h}^{-1}\right)[36]$. However, Pseudomonas pseudoalcaligenes OSS can completely degrade $3.7 \mathrm{~g} \mathrm{~L}^{-1}$ formaldehyde in $24 \mathrm{~h}$ with a degradation rate of $154 \mathrm{mg} \mathrm{L}^{-1} \mathrm{~h}^{-1}$ [37]. In previous studies, Methylobacterium sp. XJLW showed low formaldehyde tolerance $\left(1.2 \mathrm{~g} \mathrm{~L}^{-1}\right)$, and the resting cells of this strain exhibited both a very high formaldehyde tolerance $\left(60 \mathrm{~g} \mathrm{~L}^{-1}\right)$ and a high degradation rate $(1,687.5$ $\mathrm{mg} \mathrm{L}^{-1} \mathrm{~h}^{-1}$ ) in $8 \mathrm{~h}$ shake flask tests[38]. Therefore, one of the major bottlenecks is the low tolerance of the strains and low degradation rate in effluent broth, which exerts toxic effects on the microorganisms above a certain level and causes incomplete conversion of formaldehyde. To increase the tolerance of strains, research focuses can be directed to the development of highly tolerant strains by applying traditional mutagenesis and advanced technologies.

As a non-GM mutation method, random mutagenesis has been demonstrated as a powerful strategy to enhance tolerance in different microorganisms. Compared with traditional genetic engineering, atmospheric and room temperature plasma (ARTP) is a novel type of physical mutagenesis tool for creating positive microbial mutation breeding in recent years[39, 40]. ARTP driven by radiofrequency power can be generated uniformly at atmospheric pressure without any vacuum system, and the plasma can be controlled at room temperature, which is beneficial for microbial mutation. During the mutation process, the particles produced by ARTP could change the physicochemical properties of the cell wall and membrane and damage DNA molecules. Then, cells were forced to start the SOS repair mechanism with a high fault tolerance level, producing a variety of mismatch sites, which altered the metabolic networks of the target microbes. Moreover, the mutation breeding system is compact and can be operated safely and feasibly, enabling rapid, convenient, and multifaceted means of generating mutant libraries with sufficient diversity for the improvement of microbial phenotypes. The technique has been successfully employed for mutation breeding in more than 100 kinds of microbes[41], including microalgae[42], bacteria[43, 44], fungi[45, 46], yeast[47], actinomycetes[48] and marine aquaculture breeding[49].

In this study, ARTP mutagenesis technology was first applied to enhance the mutation of Pseudomonas putida to screen strains with higher tolerance to formaldehyde and degradation rates. We investigated the potential for bacteria to bioremediate formaldehyde. So the specific objectives were the following.

(a)isolate bacterial strain with high degradation rate, (b)identify and characterize bacteria isolates, (c) 
mutate and generate the mutants with higher tolerance to formaldehyde and high growth rate by ARTP mutation system, (d)investigate the degradation of formaldehyde on the mutant and genetic stability after several subcultures.

\section{Materials And Methods}

\section{Microorganisms, media and culture conditions}

Activated sludge samples were collected from a printing and dyeing plant in Wuhu (Anhui Province, China) that has a long history of using formaldehyde and aniline-contaminated materials. The sludge was placed hermetically in sterile plastic bags to induce oxygen influx and deposited at $4^{\circ} \mathrm{C}$ until microbial isolation. The sample was analyzed for properties ( $\mathrm{pH}$, formaldehyde content). The formaldehyde content in activated sludge was $362 \pm 33.6 \mathrm{mgL}^{-1}$. The $\mathrm{pH}$ value of sample was $\mathrm{pH} 7.3 \pm 0.1$. The water content was $22.4 \pm 0.2 \%$.

\section{Isolation of formaldehyde-tolerant bacteria using enrichment culture}

Five grams of activated sludge was transferred into a 300-mL Erlenmeyer flask containing $100 \mathrm{~mL}$ of Luria-Bertani (LB) broth medium in the absence of formaldehyde, which was sealed with a breathable sealing membrane to ensure a sufficient oxygen supply. The basal composition of LB medium contained $1 \%(\mathrm{w} / \mathrm{v})$ peptone, $0.5 \%(\mathrm{w} / \mathrm{v})$ dried yeast extract and $1 \%(\mathrm{w} / \mathrm{v}) \mathrm{NaCl}$, and the $\mathrm{pH}$ of the medium was adjusted from 4.0 to 10.0 with $0.1 \mathrm{M} \mathrm{NaOH}$ solution and $1.5 \%$ agar (for solid medium). It was precultured at $30^{\circ} \mathrm{C}$ under $12: 12 \mathrm{~h}$ light:dark cycles of illumination by white fluorescent light tubes on a rotary shaker (150 r.p.m.). After incubation for two days, an aliquot $(2000 \mu \mathrm{L})$ was removed from the LB flask and added into $100 \mathrm{~mL}$ mineral salt medium (MSM) aerobically with $50 \mathrm{mg} \mathrm{L}^{-1}$ formaldehyde as the sole carbon source. MSM medium was prepared in distilled water containing (in gL $\left.{ }^{-1}\right)\left(\mathrm{NH}_{4}\right)_{2} \mathrm{SO}_{4} 1.00$, $\mathrm{K}_{2} \mathrm{HPO}_{4}$ 2.16, $\mathrm{MgSO}_{4} 0.10, \mathrm{KH}_{2} \mathrm{PO}_{4} 0.85, \mathrm{MnSO}_{4} \cdot \mathrm{H}_{2} \mathrm{O} 0.05, \mathrm{CaCl}_{2} \cdot \mathrm{H}_{2} \mathrm{O} 0.03$ and $\mathrm{FeSO}_{4} .7 \mathrm{H}_{2} \mathrm{O} 0.01$ in $1 \mathrm{~L}$ distilled water with an initial $\mathrm{pH}$ of 7.0 . The inoculum was transferred to fresh MSM by $2 \%(\mathrm{v} / \mathrm{v})$. The final formaldehyde concentration in the MSM medium increased up to $100 \mathrm{mgL}^{-1}$.

Formaldehyde stock solutions were sterilized by filtration through disposable $0.2 \mu \mathrm{m}$ pore-size sterile filter units (Millipore) before addition to cold sterilized media. All instruments and media were sterilized by an autoclave $\left(121^{\circ} \mathrm{C}, 1.2 \mathrm{~atm}, 20 \mathrm{~min}\right)$ before experiments. After cultivation, the inoculum was withdrawn from $300 \mathrm{~mL}$ cultivation flasks and streaked on LB agar plates supplemented with $100 \mathrm{mg} \mathrm{L}^{-1}$ formaldehyde. The pure cultured bacteria incubated on LB were designated strain W1 and deposited.

\section{Identification Of Bacterial Strain Isolate}


The isolated bacterium was identified as Pseudomonas putida by microscopic morphological features and biochemical tests, as well as $16 \mathrm{~S}$ rRNA sequence analysis ( $99 \%$ similarity with other Pseudomonas strains according to GenBank BLAST). Following this, bacterial DNA was extracted in the laboratory using the published protocol of Oakley \& Murrel [50].

Amplification of $16 \mathrm{~S}$ rRNA genes was achieved using bacterial universal primers $27 \mathrm{~F}$ (5'AGAGTTTGATCCTGGCTCAG-3') and 1492R (5'-GGYTACCTTGTTACGACTT-3'). PCR was performed using Bio-rad thermal cycler. Each reaction $(100 \mu \mathrm{L})$ contained $1.5 \mathrm{mM} \mathrm{MgCl}_{2}, 20 \mathrm{mM}$ Tris/ $\mathrm{HCl}(\mathrm{pH} 8.4), 50 \mathrm{mM} \mathrm{KCl}$, $0.05 \%(\mathrm{v} / \mathrm{v})$ detergent, $200 \mu \mathrm{M}$ each dNTP, $1 \mathrm{ng} \mu \mathrm{L}^{-1}$ template DNA. Reaction conditions were $94^{\circ} \mathrm{C}$ for 30 sec, annealing at $54^{\circ} \mathrm{C}$ for $1 \mathrm{~min}$, polymerization at $72^{\circ} \mathrm{C}$ for $1 \mathrm{~min}$, and a final extension at $72^{\circ} \mathrm{C}$ for 10 min. Amplified nucleotide sequencing was performed by Sangong Biotech (Shanghai, China). Identification of the isolate was carried out by homology-searching BLASTn[51], and a phylogenetic tree was constructed using high-throughput sequencing to display the phylogeny of 16S rRNA.

\section{Growth of the W1 strain and measurement of formaldehyde concentration}

To evaluate the connection between the formaldehyde degradation profile and bacterial growth, the residual formaldehyde content was monitored at different intervals within $48 \mathrm{~h}$. Growth rates of the W1 strain were determined by measuring the $\mathrm{OD}_{600}$ at each point of the time course. The inoculum of the W1 strain was taken from a preculture without formaldehyde in the mid-exponential growth phase to test the solution. The initial optical density at $\mathrm{OD}_{600}$ of the $\mathrm{W} 1$ strain was approximately 0.02 . The $\mathrm{OD}_{600}$ was measured in a spectrophotometer every $2 \mathrm{~h}$ for $48 \mathrm{~h}$. A standard curve between the OD value and cell number was drawn, as shown in Fig. 1. Cell number and $\mathrm{OD}_{600}$ are highly correlated.

Samples were withdrawn from the medium and centrifuged (10,000 $\mathrm{xg}$ for $10 \mathrm{~min})$ to remove the cells. Formaldehyde in the supernatant was measured using an assay based on the Hantzsch reaction[52]. In this reaction, a sample $(1.0 \mathrm{~mL})$ was mixed with an equal volume of reagent $\mathrm{B}$ ( $2 \mathrm{M}$ ammonium acetate, $0.05 \mathrm{M}$ acetic acid and $0.02 \mathrm{M}$ Acetyacetone). After $15 \mathrm{~min}$ of incubation at $60^{\circ} \mathrm{C}$ and cooling, the reaction product of 3,5-diacetyl-1,4-dihydrolutidine was determined colorimetrially at $412 \mathrm{~nm}$. The blank contained distilled water in place of the sample. Samples with concentrations beyond this range were diluted as appropriate. As a negative control, the W1 strain was incubated for $10 \mathrm{~min}$ at $80^{\circ} \mathrm{C}$ before inoculation. Three replicate were performed for each sample. The original formaldehyde concentration in the LB medium was $100 \mathrm{mg} \mathrm{L}^{-1}$.

The cell number was determined by measuring the OD value of the culture at $600 \mathrm{~nm}$ with a spectrophotometer, and the cell number was calculated by following Eq.(1)

$y=4.218 x-0.0934 r^{2}=0.9912(1)$ 
where $x$ and $y$ are the $\mathrm{OD}_{600}$ value and cell number, respectively, which were obtained from the relationship between the cell number and OD value. The linear regression coefficient was as high as 0.9912 .

\section{Mutation procedure of P.putida by ARTP}

The ARTP breeding machine (ARTP- $₫ S$, Tmaxtree Biotechnology, Wuxi, China) consisted of a radio frequency (13-56 MHz) power supply with a pure helium supply type plasma generator. The parameters of the treatment were set as follows: the RF power input was $100 \mathrm{~W}$, the helium gas flow rate was $10 \mathrm{~L}$ $\mathrm{min}^{-1}$ and the temperature of the plasma jet was $23-30^{\circ} \mathrm{C}$. Meanwhile, the distance between the plasma torch nozzle exit and the sample plate (Dimeter) was $2 \mathrm{~mm}$. Under these determined conditions, the mutagenesis dosage by ARTP was dependent on the treatment period. To determine the optimal treatment period, $P$. putida $\mathrm{W} 1$ grown at an $\mathrm{OD}_{600}$ of $1.0-1.2$ with $5 \times 10^{8}$ cells grown in the late logarithmic phase per milliliter was collected and used for ARTP treatment. For the mutation, $10 \mu \mathrm{L}$ of an aliquot was coated on the surface of a sterilized stainless steel minidisc and placed in the chamber of the ARTP machine. The treatment time varied from $0,30,60,90,120,150$ and $180 \mathrm{sec}$. The blank control was $10 \mu \mathrm{L}$ of the original strain. After each treatment, the dry mycoderm was eluted with sterile saline into a new tube and properly diluted by serial dilution rates. Then, diluted $P$. putida solution was transferred to LB agar plates.

Aftertreatment for different times, the P.putida cell walls may be broken because of the action of the active plasma generated by ARTP. Visible colonies on LB agar plates containing $500 \mathrm{mg} \mathrm{L}^{-1} \mathrm{HCHO}$ were picked as mutants to determine the lethality rate. The individual colonies on the control medium and each mutated medium were counted. The lethality rate was calculated by following Eq.(2)

Lethality rate $\%=\frac{\mathrm{T}-\mathrm{U}}{\mathrm{T}} \times 100 \%$

where $\mathrm{T}$ and $\mathrm{U}$ are the CFU values of control colonies and surviving colonies before and after ARTP treatment, respectively.

\section{Stepwise adaption of formaldehyde and the maximum tolerated concentration (MTC) of formaldehyde assay}

After ARTP treatment, the treated colony was isolated and then promptly spread onto solid LB medium. The genetic stability of the selected mutants was also examined by a series of subcultures for formaldehyde degradation rate detection.

The maximum tolerated concentration of formaldehyde in the strain was evaluated by a dual gradient culture strategy. Each dual gradient plate was prepared with approximately $10 \mathrm{~mL}$ LB agar media without 
formaldehyde to form a slope on one side approximately $5 \mathrm{~mm}$ high. After solidification, it was put back to the horizontal position and then covered with another $10 \mathrm{~mL}$ LB agar medium supplemented with different concentrations of formaldehyde. The formaldehyde concentration was set at $500-25000 \mathrm{mgL}^{-1}$ with an interval of 1000 . The plate was designated with red arrows to confirm the direction of formaldehyde concentration (Fig. 2).

Stepwise (two steps) adaption of formaldehyde by the W1 strain was investigated. The W1 strain was incubated with $100 \mathrm{mg} \mathrm{L}^{-1}$ formaldehyde in the first step. After 24 hours of incubation, the cells were resuspended and spread onto dual gradient plates with $500 \mathrm{mg} \mathrm{L-1}$ formaldehyde at the second step. Therefore, colonies were picked up from areas with high formaldehyde concentrations and inoculated in plates with higher formaldehyde concentrations for stepwise adaptation tests. Adaptation tests were performed under culture conditions to evaluate the maximum tolerated concentration by the WT strain and the mutants.

\section{Formaldehyde Degradation by the mutant}

The mutant was inoculated ( $\left.4 \%, \mathrm{v} / \mathrm{v}, \mathrm{OD}_{600}=1.0\right)$ in $300-\mathrm{mL}$ Erlenmeyer flasks with $100 \mathrm{~mL}$ of LB broth containing different formaldehyde concentrations. An uninoculated control flask was considered a control for abiotic losses. Flasks were sealed with a breathable sealing membrane to ensure a sufficient oxygen supply and to avoid volatile organic compound loss during degradation. The concentration of formaldehyde ranged from 0.5 to $6.0 \mathrm{gL}^{-1}\left(0.5,1.0,2.0,3.0,4.0,5.0\right.$ and $\left.6.0 \mathrm{gL}^{-1}\right)$ to determine the degradation rate of formaldehyde. Each experiment was carried out in duplicate. Mean and standard deviation values were analyzed using one-way analysis of variance (ANOVA). Significance of difference was determined as $P<0.05$. To measure the possibility of formaldehyde volatilization during incubation, a control experiment without cells was conducted in the same medium and conditions.

\section{Results And Discussion}

\section{Characterization and identification of W1 strain}

The W1 strain is a gram-negative, rod-shaped bacterium $1.2 \mu \mathrm{m} \times 2.0 \mu \mathrm{m}$ in size with 2 polar flagella (Fig. 3). It could grow at a wide range of $\mathrm{pH}$ values from 4.0-9.0, with the optimal $\mathrm{pH}$ determined to be 7.0-7.5. Meanwhile, the $\mathrm{W} 1$ strain could grow at a wild temperature range of $10-45^{\circ} \mathrm{C}$, with an optimal temperature range of $30-37^{\circ} \mathrm{C}$. Biochemical tests were negative for gelatinase and oxidase. The W1 strain was observed to grow on glucose, lactose and sucrose. However, the W1 strain could not degrade starch and gelatin and was negative for pyocyanin production and denitrification (Table 1).

The 16S rDNA gene was amplified by PCR, and the length of the sequence was $1485 \mathrm{bp}$. The accession number in GenBank was MZ497031. The strain was shown to be a closely related member of the genus 
Pseudomonas, and the similarity was $99 \%$. The phylogenetic tree is shown in Figure 4 . Therefore, the isolate W1 strain was identified as P. putida based on the above characteristics. 
Table 1

Characteristics of W1 strain

\begin{tabular}{|ll|}
\hline Characteristic & W1 Strain \\
\hline Size $(\mu \mathrm{m})$ & $1.2 \times 2.0$ \\
\hline shape & Rod-shaped \\
\hline Number of polar flagella & 2 \\
\hline Gram-staining & Gram-negative \\
\hline Temperature $\left.{ }^{\circ} \mathrm{C}\right)$ & $10-45$ \\
Range & $30-37$ \\
Optimum & \\
\hline pH & $4.0-10.0$ \\
Range & $7.0-7.5$ \\
Optimum & \\
\hline Methyl red test & - \\
\hline Indole test & - \\
\hline oxidase & + \\
\hline Voges-Proskauer test & - \\
\hline Hydrogen sulfide test & + \\
\hline Suger utilization: & + \\
\hline Glucose & + \\
\hline Sucrose & - \\
\hline lactose & - \\
\hline Hydrolysis of : & - \\
\hline Gelatin & - \\
\hline Starch & \\
\hline Dyovendin production + : positive; $:$ negative & - \\
\hline
\end{tabular}




\section{Formaldehyde degradation by the growing cells and resting cells of P. putida W1 in shake flasks}

Changes in cell density and formaldehyde concentration in the medium with the passage of incubation are shown in Figure 4. Initially, the growth curve of the $\mathrm{W} 1$ strain exposed to $100 \mathrm{mg} \mathrm{L}^{-1}$ showed a lag phase of $8 \mathrm{~h}$, suggesting that the degradation rates of growth at low cell density were low. Next, the formaldehyde concentration in the medium began to decrease when the $\mathrm{OD}_{600}$ reached $0.056(8 \mathrm{~h})$. Approximately $12 \%$ formaldehyde was degraded in shaking falsks when the $\mathrm{OD}_{600}$ reached $0.105(10 \mathrm{~h})$ with a cell number of $3.49 \times 10^{7}$. The $W 1$ cells were able to grow at an exponential phase until $40 \mathrm{~h}$ to a stable period with an $\mathrm{OD}_{600}$ value of 0.68 (cell numbers up to $2.77 \times 10^{8}$ ). The strain W1 nearly removed $92 \%$ of formaldehyde. These results indicated that the decrease in formaldehyde concentration depended on the increased cell number of the W1 strain.

Eventually, $98 \%$ of $100 \mathrm{mg} \mathrm{L}^{-1}$ formaldehyde in the medium was degraded after $48 \mathrm{~h}$. Considering these results, the tolerance and degradation ability of the W1 strain was improved by adapting the formaldehyde concentration. The adaptation of formaldehyde is important for degrading high concentrations of formaldehyde.

\section{Obtaining mutant strains by ARTP}

P. putida W1 was mutated by the new mutation tool ARTP. Different mutagenic treatment times were set from $30 \mathrm{sec}$ to $180 \mathrm{sec}$. The suspension was diluted to $10^{-4}$ on spread LB plates supplemented with 500 $\mathrm{mg} \mathrm{L}^{-1}$ formaldehyde for counting. Each group had three parallel samples. $0 \mathrm{~s}$ was used as a control to calculate the mutagenic mortality rates. As shown in Figure 6, when the treatment time was $30 \mathrm{sec}, 60$ $\mathrm{sec}$ and $90 \mathrm{sec}$, the mortality rate reached $92.5 \%, 97 \%$ and $98 \%$, respectively. When the time exceeded 120 seconds, the fatality rate reached $99.25 \%$. After 150 seconds of ARTP treatment, there were no longer cells alive on the plates. According to the modern theory of breeding, when the mortality rate of microorganism mutagenesis was over $95 \%$, the positive mutation rate was the highest, and the mutation effect was the optimum. Therefore, to improve the maximum tolerated concentration and efficiency, subsequent mutagenesis treatment times of $90 \mathrm{sec}$ and $120 \mathrm{sec}$ were selected for mutant screening. Two formaldehyde-tolerant $P$. putida variants named WMZ120-5 and WMZ 90-1 were obtained by ARTP with lethality rates greater than $98 \%$. ARTP could be an effective way to cause mutations in target microorganisms. Colonies were deposited for subsequent experiments.

\section{Mutant screening and the assessment of the maximum tolerated concentration (MTC) of formaldehyde}


To characterize the response of $P$. putida mutants after ARTP mutation to formaldehyde, we prepared fourteen gradient plates of LB supplemented with different formaldehyde concentrations $\left(0.5-25.0 \mathrm{~g} \mathrm{~L}^{-1}\right)$ to measure the maximum tolerated concentration (MTC) using dual gradient plates. Plating efficiency was tested on agar plates after incubation for $96 \mathrm{~h}$ with formaldehyde. The variants exhibited regular growth behavior in gradient plates and reached different colony forming units (CFU/ml) in the presence of various concentrations of formaldehyde. WT P. putida W1 was incubated as a negative control. The statistical results of CFU with different concentration gradient plates are shown in Table 2.

Table 2

The relationship between the $\mathrm{CFU}$ and the maximum tolerated concentration of FA under gradient plates

\begin{tabular}{|c|c|c|c|}
\hline \multirow{3}{*}{$\begin{array}{l}\text { Formaldehyde Concentration } \\
\left(\mathrm{g} \mathrm{L}^{-1}\right)\end{array}$} & \multicolumn{3}{|c|}{ Strain cultivation/Mean value of CFU } \\
\hline & \multirow[t]{2}{*}{ Wild-type strain W1 } & Mutant strain & Mutant strain \\
\hline & & WMZ90 & WMZ120 \\
\hline 0.5 & 80 & $>200$ & $>200$ \\
\hline 1 & 28 & $>200$ & $>200$ \\
\hline 2 & 8 & $>200$ & $>200$ \\
\hline 3 & - & $>200$ & $>200$ \\
\hline 4 & - & $>200$ & $>200$ \\
\hline 5 & - & 150 & 150 \\
\hline 6 & - & 50 & 150 \\
\hline 7 & - & 27 & 150 \\
\hline 8 & - & 12 & 100 \\
\hline 9 & - & $2-3$ & 80 \\
\hline 10 & - & - & 70 \\
\hline 15 & - & - & 52 \\
\hline 20 & - & - & - \\
\hline 25 & - & - & - \\
\hline
\end{tabular}

Table 2 shows that the parental wild-type $\mathrm{W} 1 \mathrm{grew}$ poorly at formaldehyde concentrations up to $1.0 \mathrm{~g} \mathrm{~L}^{-1}$. As the formaldehyde concentration continued to rise to $2.0 \mathrm{gL}^{-1}$, only 8 colonies were formed on the 
plates. Concentrations exceeding $3.0 \mathrm{gL}^{-1}$ and $4.0 \mathrm{gL}^{-1}$ inhibited $\mathrm{W} 1$ growth completely, suggesting that growing cells are unable to tolerate formaldehyde $\left(>2.0 \mathrm{~g} \mathrm{~L}^{-1}\right)$ due to toxicity. Compared to strain W1, mutants could withstand relatively higher formaldehyde. Colonies of WMZ90 remained after incubation in $8.0 \mathrm{gL}^{-1}$ formaldehyde. A few colonies were still formed with $9.0 \mathrm{~g} \mathrm{~L}^{-1}$ formaldehyde added, and the tolerance increased fourfold. Meanwhile, WMZ120 grew well at a formaldehyde concentration of $10.0 \mathrm{~g}$ $\mathrm{L}^{-1}$. Although the colonies were small, WMZ120 was a highly formaldehyde-resistant formaldehyde utilizer. Compared to W1, the MTC of WMZ120 to formaldehyde was $15.0 \mathrm{gL}^{-1}$, with fold-change $\geq 7.5$ and $\mathrm{P} \leq 0.05$.

After culturing the mutation samples of strain WMZ120 for 5 days, well-grown colonies were chosen and inoculated in $15.0 \mathrm{~g} \mathrm{~L}^{-1}$ formaldehyde dual-gradient agar plates. A total of 50 strains were primarily screened in the higher formaldehyde concentration area. Three parallel mutants were set up in each group. Third round of screening tests with MTC of formaldehyde were performed, and 17 key strains were selected, which ensured the optimum results. Among them, the optimal mutant strain named WMZ120-5 was observed to have the highest formaldehyde tolerance. After subculture for $48 \mathrm{~h}$, colonies of WMZ120-5 were still formed slightly on the $20.0 \mathrm{~g} \mathrm{~L}^{-1}$ formaldehyde gradient plate, and the formaldehyde tolerance concentration reached $20.0 \mathrm{~g} \mathrm{~L}^{-1}$, which was 7- or 10-fold higher than that of the wild-type strain.

Apparently, the formaldehyde tolerance of the WMZ120-5 mutant was significantly improved by the ARTP mutant. Formaldehyde degradation characteristics of mutant WMZ120-5 in shake flasks

To determine the response to formaldehyde in liquid medium, the effects of formaldehyde concentrations and optical density were investigated in shake flasks. The assay was monitored in duplicate at seven initial concentrations of formaldehyde between 0.5 and $6.0 \mathrm{~g} \mathrm{~L}^{-1}$ during growth of mutant strain WMZ120-5. The suspension of $1 \mathrm{~mL}$ bacteria was extracted from 0 to $144 \mathrm{~h}$, and the formaldehyde content was measured according to the formaldehyde standard curve drawn by the acetylacetone method. The addition of formaldehyde resulted in a concentration-dependent decrease in the growth rate, while the final cell density was not affected when $3 \mathrm{~g} \mathrm{~L}^{-1}$ or less formaldehyde was added (Fig. 7a). The addition of more than $4 \mathrm{~g} \mathrm{~L}^{-1}$ resulted in a considerable lag phase, and concentrations higher than $5 \mathrm{~g}$ $\mathrm{L}^{-1}$ completely inhibited growth. Complete degradation of formaldehyde by $P$. putida occurred within 144 h, demonstrating the presence of a formaldehyde degradation system in P. putida WMZ120-5.

The results (Fig. 7b) showed that the degradation rates of the initial formaldehyde concentrations $(0.5$ and $1.0 \mathrm{~g} \mathrm{~L}^{-1}$ ) were nearly $100 \%$ at $8 \mathrm{~h}$ and $12 \mathrm{~h}$ when the OD600 reached 0.76 and 0.85 , respectively. The control experiments (cell-free) showed that formaldehyde volatilization from the media (containing 0.1 $\mathrm{gL}^{-1}$ formaldehyde) was negligible in the shake flasks. Direct cultivation of strain WMZ120-5 cells was found to be impossible in LB liquid cultures at an initial formaldehyde concentration of $6.0 \mathrm{gL}^{-1}$ (data not shown). Therefore, stepwise acclimatization of the culture at increasing concentrations of formaldehyde (typically 3.0, 4.0, 5.0 and then $6.0 \mathrm{~g} \mathrm{~L}^{-1}$, with approximately 24-hour intervals between successive 
increases in concentration) allowed the cells to survive at formaldehyde concentrations up to $6.0 \mathrm{~g} \mathrm{~L}^{-1}$. Upon exposure to a formaldehyde concentration of $5.0 \mathrm{gL}^{-1}$, the growth of the strain was not observed, and then the cell density reached a plateau, while formaldehyde removal proceeded at a roughly uniform level. The cultures underwent a period of nongrowth when the $\mathrm{OD}_{600}$ reached 0.25 with a lag phase of 48 h. Then, before the formaldehyde concentration of $6.0 \mathrm{~g} \mathrm{~L}^{-1}$ fell, growth could resume when the $\mathrm{OD}_{600}$ reached 0.16 with a lag phase of $96 \mathrm{~h}$. Eventually, the cells were able to tolerate up to $4.0 \mathrm{~g} \mathrm{~L}^{-1}$ formaldehyde and degraded $77.5 \%$ of it within $144 \mathrm{~h}$, with $50 \%$ of $5.0 \mathrm{~g} \mathrm{~L}-1$ and $27 \%$ of $6.0 \mathrm{~g} \mathrm{~L}^{-1}$, respectively. Considering these results, the degradation ability of formaldehyde by the WMZ120-5 strain was improved by stepwise increasing the formaldehyde concentration (Fig. 7a and 7b).

\section{Genetic stability of subculture}

After ARTP mutagenesis, we succeeded in subculturing the mutant strain, which was adapted to a high formaldehyde concentration in LB medium. To verify whether the WMZ120-5 mutant showed highly stable genetic stability, an initial formaldehyde concentration of $3.0 \mathrm{~g} \mathrm{~L}^{-1}$ was selected for investigation in the experiment. They were subcultured every generation for $96 \mathrm{~h}$, and the OD and degradation rate were measured by the end of the tests. In the process of mutation and screening, the same species of strain were subcultured three times. Therefore, research on the genetic stability of strain WMZ120-5 was performed from the fourth generation to the tenth generation, and the experimental results are shown in Table 3. For the fourth generation, we obtained a $98 \%$ degradation rate of formaldehyde based on the $0 D 600 \mathrm{~nm}$ value of 0.878 . The results showed no significant difference in the degradation rate of formaldehyde after the 10th subculture (Table 3). 
Table 3

Analysis of different generations of mutation strain WMZ120-5

\begin{tabular}{|c|c|c|}
\hline Generation NO. & $\begin{array}{l}\text { OD } \\
h\end{array}$ & $\begin{array}{l}\text { Degradation rate(\%) with initial formaldehyde concentration of } \\
3.0 \mathrm{~g} \mathrm{~L}^{-1} \\
\text { within } 96 \mathrm{~h}\end{array}$ \\
\hline $\mathrm{F}_{4}$ & 0.878 & 98 \\
\hline $\mathrm{F}_{5}$ & 0.842 & 93 \\
\hline $\mathrm{F}_{6}$ & 0.862 & 96 \\
\hline $\mathrm{F}_{7}$ & 0.848 & 95 \\
\hline $\mathrm{F}_{8}$ & 0.876 & 98 \\
\hline $\mathrm{F}_{9}$ & 0.865 & 96 \\
\hline$F_{10}$ & 0.871 & 97 \\
\hline Mean value & 0.863 & 96 \\
\hline Standard Deviation & 0.014 & 1.773 \\
\hline $\begin{array}{l}\text { Coefficient of } \\
\text { Variation }\end{array}$ & $1.589 \%$ & $1.843 \%$ \\
\hline
\end{tabular}

Figure 8 shows that the OD value of strain WMZ120-5 was basically stable after successive subcultures. The average value of $\mathrm{OD} 600 \mathrm{~nm}$ was 0.863 , while the degradation rate ranged from $93-98 \%$. The growth value of the mutant strain was consistent with the degradation rate of formaldehyde, showing a good correlation. Strain WMZ120-5 showed quick environmental adaptability to a $3.0 \mathrm{~g} \mathrm{~L}^{-1}$ formaldehyde concentration and consumed it completely within 96 hours. The coefficient of variation represented the degree of variation. In this study, the coefficient of variation and the mean value of formaldehyde degradation of the strain were $1.843 \%$ and $96 \%$, respectively. The results showed no significant difference in the degradation rate of formaldehyde after the 10th subculture experiment: formaldehyde $\left(3.0 \mathrm{~g} \mathrm{~L}^{-1}\right)$ was degraded completely within $96 \mathrm{~h}$ in all cases.

The reason for the genetic stability of the mutant strains by ARTP might be that ARTP has a higher positive gene response effect than traditional physical and chemical mutagenesis technology. ARTP has the unique potential to develop efficient mutant strains in the shortest time (Wang et al.,2010), and highenergy active particles could repair DNA damage; thus, the characteristics of the mutant strains could be stably inherited by offspring.

\section{Conclusions}


In this study, formaldehyde was utilized by newly isolated Pseudomonas. putida original strain was significantly improved by a novel ARTP mutagenesis tool to alter formaldehyde tolerance and degradation rate. Although the original strain $\mathrm{W} 1$ showed low formaldehyde tolerance $\left(2.0 \mathrm{~g} \mathrm{~L}^{-1}\right)$, the mutant strain WMZ120-5 exhibited both a very high formaldehyde tolerance $\left(20.0 \mathrm{~g} \mathrm{~L}^{-1}\right)$ after stepwise and a high degradation rate, as observed in $96 \mathrm{~h}$ shake flask tests at a formaldehyde concentration of 3.0 $\mathrm{gL}^{-1}$.

The P. putida mutant WMZ120-5 acclimatized at modest formaldehyde levels can detoxify formaldehyde at concentrations that are too high to support normal growth. The highest concentration of formaldehyde that supports growth of the mutant WMZ120-5 is remarkably tolerant to formaldehyde 7 -fold higher than that of the original strain W1. To verify the genetic stability of the mutant strain, the growth density and formaldehyde degradation rate of the mutant strain were determined through 10th subcultures. The results showed that the mutant strain maintained a stable formaldehyde degradation rate. Nonetheless, upon exposure to a high concentration of formaldehyde $\left(\geq 5 \mathrm{~g} \mathrm{~L}^{-1}\right)$, formaldehyde removal by the strain proceeded with a slow degradation rate. The fact is that the lower concentration of formaldehyde is consistent with the higher degradation rate consumed by the strain mutant. The evidence currently available suggests that many of these changes may be acquired because of the plasma generated by ARTP. ARTP is driven by pure helium, which penetrates the cell wall and cell membrane and then damages DNA and proteins, thereby creating mutations by damaging the genome in the cells. This is the first report about the evolution of a $P$. putida strain using ARTP methods to improve its high tolerance to formaldehyde.

These results strongly suggest that strain WMZ120-5 could be a potential candidate for formaldehyde biodegradation and that stepwise adaptation is worthy of further development for continuous formaldehyde degradation treatment. So it is our expectation that Pseudomonas. putida WMZ120-5 will be used as bioremediation of formaldehyde in the treatment of wastewater. Assuming that strain MWZ120-5 can adapt to life at high formaldehyde concentrations, it is expected that formaldehyde will be removed using domestication combined with gradient adding concentration by the WMZ120-5 strain.

\section{Declarations}

Author Contribution Sample collection, microscopic detection, strain screening, mutation, data processing, analysis, writing-original draft and editing were performed by Fang Kong. Molecular biology studies of strains were analyzed by Ming Wei. Writing-review and editing were performed by Weirong Cai. Funding acquisition, project administration, resources, supervision, validation, writing review and editing were performed by Youping Wang. All authors read and approved the final manuscript.

Funding This work received financial support from the Postdoctoral Science Foundation of China (2013M541735), the Postdoctoral Science Foundation of Jiangsu Province (1301048B), and the preresearch Natural Science Foundation of Anhui Polytechnic University (2016yyzr07). 
Ethics Approval This article does not contain any studies with human participants performed or animals by any of the authors.

Consent to Participate Not applicable.

Consent for Publication All authors read and approved the final manuscript.

Conflict of Interest The authors declare no competing interests.

Data Availability All data and materials generated or analyzed during this study are included in this published article.

\section{References}

1. Heck, HD., Casanova, M., Starr TB. (1990). Formaldehyde toxicity-new understanding. Critical reviews in toxicology, 20, 397-426.

2. Resendes, AS., Dos, SDS., França, FM., Petesse, ML., Badaró-Pedroso Cintia, FCM. (2018). Acute toxic and genotoxic effects of formalin in Danio rerio (zebrafish). Ecotoxicology, 27(10),1379-1386.

3. Stephen, WK., Jackson, W., Kawira, M., Murithi, G. (2019). Formaldehyde Use and Alternative Biobased Binders for Particleboard Formulation: A Review. Journal of chemistry,1-12

4. Schechter, DS., Singer, PC.(1995). Formation of Aldehydes During Ozonation. Ozone Science \& Engineering, 17(1),53-69.

5. Nielsen, GD, Larsen, ST, Wolkoff, P. (2017). Re-evaluation of the WHO(2010) formaldehyde indoor air quality guideline for cancer risk assessment. Archives Of Toxicology, 91(1),35-61.

6. Huang, SD.,Wei, WJ.,Louise, B. W.,Tunga, S.,Haidong, K.,Bu, ZM., Zhang, YP. (2017). Indoor formaldehyde concentrations in urban China: Preliminary study of some important influencing factors.Science of the total environment, 590,394-405.

7. Tham KW. (2016).Indoor air quality and its effects on humans-A review of challenges and developments in the last 30 years. Energy \& Buildings, 130,637-650.

8. Jean-Baptiste, S., Angela, SS., Maria, TI., Sandrine, M., Jaafar, G., Franck, B., Alain, C., Vanessa, F. (2020).Nanostructured tin oxide materials for the sub-ppm detection of indoor formaldehyde pollution.Talanta,208.

9. Tunga S. (2019).Formaldehyde sources, formaldehyde concentrations and air exchange rates in European housings. Buliding and environment, 150, 219-232.

10. Nicholas, B., Mustafa, AlZ., Michael, B., Robert, A. B., Jan, Z.,Daniel, K.(2019). Overview of biological mechanisms of human carcinogens. Journal of Toxicology and Environmental Health, Part B, 22,7-8, 288-359.

11. Huang, Y., Ho, SSH., Lu, YF, Niu, RY., Xu, LF. (2016).Removal of Indoor Volatile Organic Compounds via Photocatalytic Oxidation: A Short Review and Prospect.Molecules, 21(1),56-76. 
12. Michael, F., Armen, N., Siegfried, K. (2016).A systematic review of the association between occupational exposure to formaldehyde and effects on chromosomal DNA damage measured using the cytokinesis-block micronucleus assay in lymphocytes. Mutation Research/Reviews In Mutation Research,770(Pt A),46-57.

13. Wei, CX., Wen, HX, Yuan, LY., McHale, C.M., Li, H., Wang, K., Yuan, JL., Yang, X., Zhang, LP. (2017).Formaldehyde induces toxicity in mouse bone marrow and hematopoietic stem/progenitor cells and enhances benzene-induced adverse effects. Archives of toxicology, 91(2),921-933.

14. Guillermo, BB., Niek, W., Johannes, M., Felix, AD., Matthias, P., Lee, M., Lucas, BP., Ivan, VR., Thomas, FB., Rebecca, LC., Paul, SM., Christopher, JC., Alexei, V., Ketan, JP. (2017).Mammals divert endogenous genotoxic formaldehyde into onecarbon metabolism. Nature, 548(7669),549-554.

15. Cheng, J., Zhang, L., Tang, Y., Li, Z. (2016). The toxicity of continuous long-term low-dose formaldehyde inhalation in mice. Immunopharmacology And Immunotoxicology, 38(6),495-501.

16. Leng, J., Liu, CW., Hartwell, HJ., Yu, R., Lai, Y., Bodnar, WM., Lu, K., Swenberg, JA.(2019). Evaluation of inhaled low-dose formaldehyde-induced DNA adducts and DNA-protein cross-links by liquid chromatography-tandem mass spectrometry. Archives Of Toxicology,93(3),763-773.

17. Pontel, LB., Rosado, IV., Burgos-Barragan, G., Garaycoechea, Jl., Yu, R., Arends, MJ., Chandrasekaran, G., Broecker, V., Wei, W., Liu, L., Swenberg, JA., Crossan, GP., Patel, KJ. (2015).Endogenous Formaldehyde Is a Hematopoietic Stem Cell Genotoxin and Metabolic Carcinogen. Molecular Cell, 60(1),177-188.

18. Chen, NH., Djoko, KY., Veyrier, FJ., McEwan, AG. (2016).Formaldehyde Stress Responses in Bacterial Pathogens. Frontiers in microbiology,7(257),1-17.

19. Qin, YM., Wang, ZN., Jiang, JT., Xing, LB.,Wu, K. (2020).One-step fabrication of TiO2/Ti foil annular photoreactor for photocatalytic degradation of formaldehyde.Chemical Engineering Journal,394.

20. Gao, RQ., Qian, S., Zhi, F., Li, GT., Jia, MZ. (2018).Preparation of nano-TiO2/ diatomite-based porous ceramics and their photocatalytic kinetics for formaldehyde degradation. International Journal of Minerals, Metallurgy, and Materials, 25(1),73-79.

21. Zhang, W., Cheng, H., Niu, Q., Fu, M., Huang, H., Ye, D. (2019).Microbial targeted degradation pretreatment: A novel approach to preparation of activated carbon with specific hierarchical porous structures, high surface areas, and satisfactory toluene adsorption performance. environmental science \& technology, 53, 7632-7640.

22. Zhao, SY., Zhao, YY., Liang, HX. Su, YH. (2019).Formaldehyde removal in the air by six plant systems with or without rhizosphere microorganisms. International Journal of Phytoremediation, 21(13),1296-1304.

23. Shao, YH.,Wang, YX., Zhao, R.,Chen, JM., Zhang, F.M. (2020).Biotechnology progress for removal of indoor gaseous formaldehyde.Applied Microbiology and Biotechnology,104(9),3715-3727.

24. Yonemitsu, H., Shiozaki, E., Hitotsuda, F., Kishimoto, N., Okuno, Y. (2016).Biodegradation of high concentrations of formaldehyde by lyophilized cells of Methylobacterium sp. FD1.Bioscience, Biotechnology, and Biochemistry, 80(11),2264-2270. 
25. Ezhilkumar, P., Sivakumar, VM., Yogasri, A., Thirumarimurugan, M. (2017).Biodegradation of formaldehyde using Bacillus subtilis in batch process. International Journal of Materials \& Product Technology, 55(1-3),296.

26. Hiroshi, Y., Yuta, K.(2018). Biodegradation of high concentrations of formaldehyde using Escherichia coli expressing the formaldehyde dismutase gene of Methylobacterium sp. FD1.Bioscience, Biotechnology, and Biochemistry,82, 49-56.

27. Jin, M., Yu, X., Chen, XL.,Zeng, RY. (2016).Pseudomonas putida IOFA1 transcriptome profiling reveals a metabolic pathway involved in formaldehyde degradation. Process Biochemistry,51(2), 220-228.

28. Wang, ML., Xu, SM., Li,SY.,Zhu,RC.(2019).Isolation of formaldehyde-degrading bacteria and the evaluation of the degradation characteristics.Journal of Industrial and Engineering Chemistry,75,224-229.

29. Morales, P., Cáceres, M., Scott, F., Díaz-Robles, L., Aroca, G.,Vergara-Fernández, A. (2017).Biodegradation of benzo[a]pyrene, toluene, and formaldehyde from the gas phase by a consortium of Rhodococcus erythropolis and Fusarium solani. Applied Microbiology and Biotechnology, 101(17),6765-6777.

30. Ezhilkuma, P., Sivakumar, VM., Yogasri, A., Thirumarimurugan, M.(2017). Biodegradation of formaldehyde using Bacillus subtilis in batch process. International Journal of Materials and Product Technology,55, 1/2/3,296-307.

31. Atsushi, M.,Ryuichi, K., Motoaki, S., Satoshi, O.(2017).The Gene of Aspergillus oryzae Involved in Degradation of Formaldehyde and Formaldehyde Degradation in Vapour Phase by Porous Enzyme/Chitosan Nanofibre Composites. Journal Of Polymers And The Environment, 25(4),12731279.

32. Takuji, O., Yuji, K., Kazufumi, O., Yoichi, K., Kohsai, F., Kazuhiro, N., Keisuke, E., Yoshiyuki, N.(2015). Isolation, sequencing, and heterologous expression of the Paecilomyces variotii gene encoding $\mathrm{S}$ hydroxymethylglutathione dehydrogenase (fldA). Applied Microbiology and Biotechnology, 99 (4), 1755-1763.

33. Yoshida, K., Ishii, H., Ishihara, Y., Saito, H., Okada, Y.(2009). Bioremediation potential of formaldehyde by the marine microalga Nannochloropsis oculata ST-3 strain. Applied Biochemistry And Biotechnology, 157,321-328.

34. Shinagawa, E., Toyama, H., Matsushita, K., Tuitemwong, P., Theeragool, G., Adachi, O. (2006).A novel type of formaldehyde-oxidizing enzyme from the membrane of Acetobacter sp. SKU 14. Bioscience, Biotechnology, and Biochemistry,7,850-857.

35. Lessmeier, L., Hoefener, M., Wendisch, VF. (2013). Formaldehyde degradation in Corynebacterium glutamicum involves acetaldehyde dehydrogenase and mycothiol-dependent formaldehyde dehydrogenase. Microbiology,159, 265-2662.

36. Iwahara, M., Fukuda, R., Nakahara, K., Suzuki, K., Tanaka, T., Nomura, Y.(2002). Isolation and properties of Paecilomyces sp. no. 5 capable of degrading high concentrations of formaldehyde. Biocontrol Science, 7,107-110. 
37. Mirdamadi, S., Rajabi, A., Khalilzadeh, P., Norozian, D., Akbarzadeh, A., Mohseni, F.A. (2005).Isolation of bacteria able to metabolize high concentrations of formaldehyde. World Journal Of Microbiology \& Biotechnology, 21, 1299-1301.

38. Qiu, LQ., Chen, WW, Zhong, L., Wu, WX., Wu, SJ., Chen, JM., Zhang, FM., Zhong,WH. (2014).Formaldehyde biodegradation by immobilized Methylobacterium sp. XJLW cells in a threephase fluidized bed reactor. Bioprocess And Biosystems Engineering, 37,1377-1384.

39. Zhang, X., Zhang, XF., Li, HP., Wang, LY, Zhang, C., Xing, XH., Bao, CY. (2014).Atmospheric and room temperature plasma (ARTP) as a new powerful mutagenesis tool. Applied Microbiology and Biotechnology,98(12),5387-5396.

40. Zhang, X., Zhang, XF, Wang, L., Zhang, C., Tan, Y., Chang, HB, Li, HP, Xing, XH. (2014).Recent progress on atmospheric and room temperature plasma mutation breeding technology and its applications. CIESC Journal, 65 (7), 2676-2684.

41. Ottenheim, C., Nawrath, M., Wu, JC. (2018).Microbial mutagenesis by atmospheric and roomtemperature plasma (ARTP): the latest development. Bioresour Bioprocess, 5, 464.

42. Liu, B., Sun, Z., Ma, X., Yang, B., Jiang, Y., Wei, D., Chen, F. (2015).Mutation breeding of extracellular polysaccharide-producing microalga Crypthecodinium cohnii by a novel mutagenesis with atmospheric and room temperature plasma. International Journal Of Molecular Sciences,16, 82018212.

43. Nyabako, BA., Fang, H., Cui, FJ.,Liu, KY., Tao, TL., Zan, XY., Sun, WJ.(2020). Enhanced Acid Tolerance in Lactobacillus acidophilus by Atmospheric and Room Temperature Plasma (ARTP) Coupled with Adaptive Laboratory Evolution (ALE).Applied Biochemistry and Biotechnology,191 (4),1499-1514.

44. Liu, KY., Fang, H., Cui, FJ., Nyabako, BA, Tao, TL., Zan, XY.,Chen, HY., Sun, WJ. (2020).ARTP mutation and adaptive laboratory evolution improve probiotic performance of Bacillus coagulans. Applied Microbiology and Biotechnology. 104,6363-6373.

45. Shi, F., Tan, J., Chu, J., Wang, Y., Zhuang, Y., Zhang, S.(2015). A qualitative and quantitative highthroughput assay for screening of gluconate high-yield strains by Aspergillus niger. Journal of Microbiological Methods, 109,134-139.

46. Gao, XL., Liu, EM.,Yin, YY.,Yang, LX., Huang, QR., Chen, S., Ho, CT. (2020).Enhancing Activities of SaltTolerant Proteases Secreted by Aspergillus oryzae Using Atmospheric and Room-Temperature Plasma Mutagenesis.Journal of agricultural and food chemistry, 68(9), 2757-2764.

47. Zheng, SM., Jiang, B., Zhang, T., Chen, JJ. (2020).Combined mutagenesis and metabolic regulation to enhance d-arabitol production from Candida parapsilosis. Journal of Industrial Microbiology \& Biotechnology: Official Journal of the Society for Industrial Microbiology and Biotechnology, 47 (6),425-435.

48. Shen, XJ., Zhang, P., Shi, YP. (2015).A mutation strain with high erythromycin yield obtained by using novle atmosphericand room temperature plasmas and UV mutation.China Journal of Veterinary Medicine,49(1),19-23. 
49. Hou, JL., Zhang, XY., Wang, GX., Sun, ZH.,Du, W., Zhao, YX.,Wang, LY., Xing, XH., Wang, YF.(2019). Novel breeding approach for Japanese flounder using atmosphere and room temperature plasma mutagenesis tool. BMC genomics,20(1):323-339.

50. Oakley, CJ., Murrell, JC.(1988). nifH genes in the obligate methane oxidising bacteria. Fems Microbiology Letters, 49, 53-57.

51. Thompson, JD., Gibson, TJ., Plewniak, F., Jeanmougin, F., Higgins, DG. (1997).The CLUSTAL_X windows interface: flexible strategies for multiple sequence alignment aided by quality analysis tools.Nucleic acids research, 25(24),4876-4882.

52. Nash, T. (1953).The colorimetric estimation of formaldehyde by means of the Hantzsch reaction. Biochemical Journal, 55,416-421.

\section{Figures}

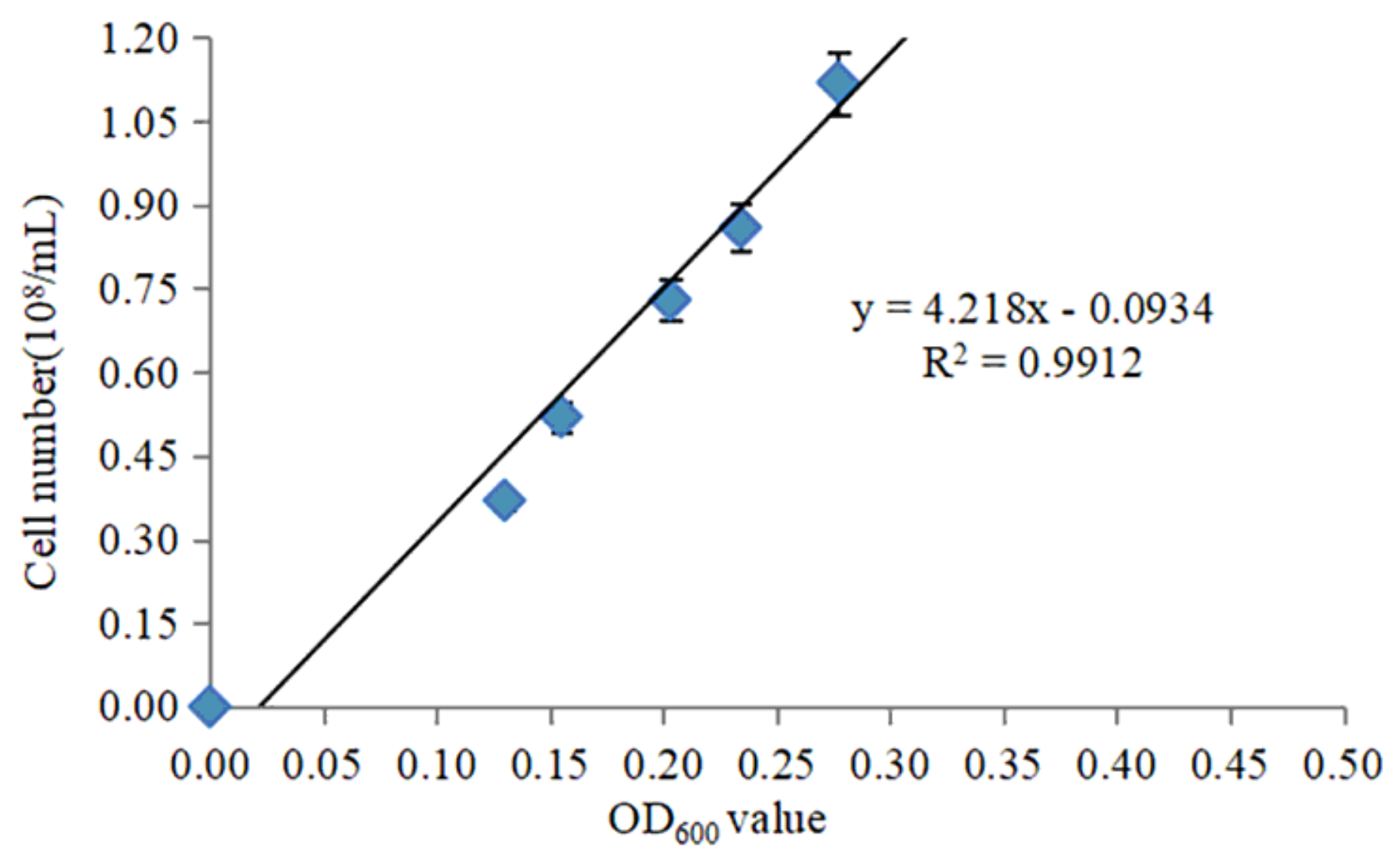

\section{Figure 1}

The correlation between the $\mathrm{OD}_{600}$ value and cell number $\left(10^{8} / \mathrm{mL}\right)$ 


\section{Figure 2}

Simulated diagram of screening of mutants tolerant to high concentrations of formaldehyde in dual gradient medium. (a) The formaldehyde concentration of the medium was a linear gradient, with a formaldehyde area (red) and an absent area (blue). (b) Mutated colonies appeared on the surface of the medium at high formaldehyde concentrations and then picked out.

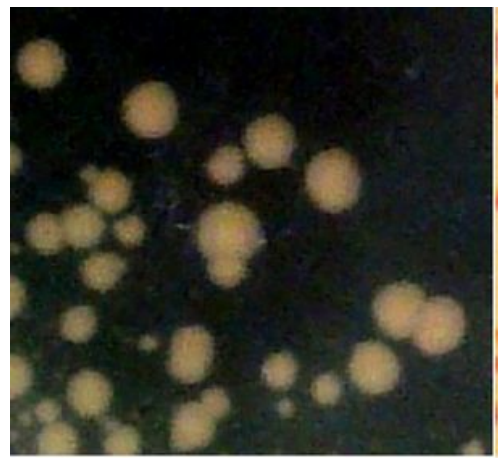

3a

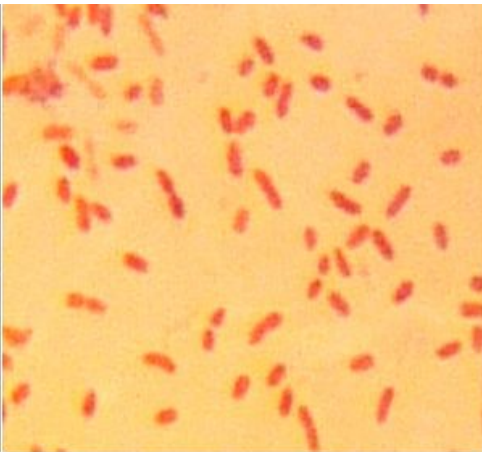

$3 \mathbf{b}$

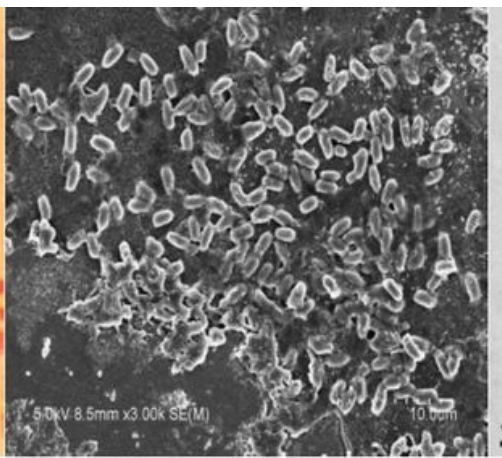

$3 \mathrm{c}$

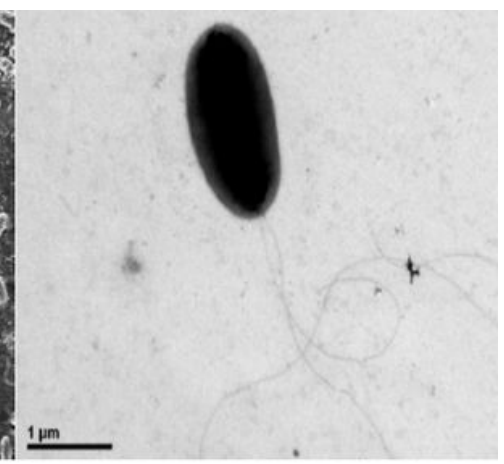

3d

\section{Figure 3}

Colonial morphology and micrographs of W1 observed under an optical microscope

(3a) Colonial morphology; (3b) Gram staining (negative) (100x oil immersion lens); (3c) Micrograph by SEM (5.0 kV, $8.5 \mathrm{~mm} \times 3.00 \mathrm{k})$; (3d) strain with 2 polar flagella

\section{Figure 4}

Phylogeneric tree for the taxonomic location of strain (test sequence) W1 obtained from the highthroughput sequencing method based on the 16S rRNA gene sequence. Numbers represent the sequences' accession numbers in GenBank.

\section{Figure 5}

Growth profile of the W1 strain grown on LB liquid medium containing formaldehyde at a final concentration of $100 \mathrm{mg} \mathrm{L}^{-1}$. Changes in cell density and formaldehyde concentration in the medium were measured within $48 \mathrm{~h}$ after inoculation. Growth of W1( $\mathbf{\Delta})$ and formaldehyde content $(\boldsymbol{\square})$ in the medium are shown. Bars indicate the standard error from the three individual experiments. 


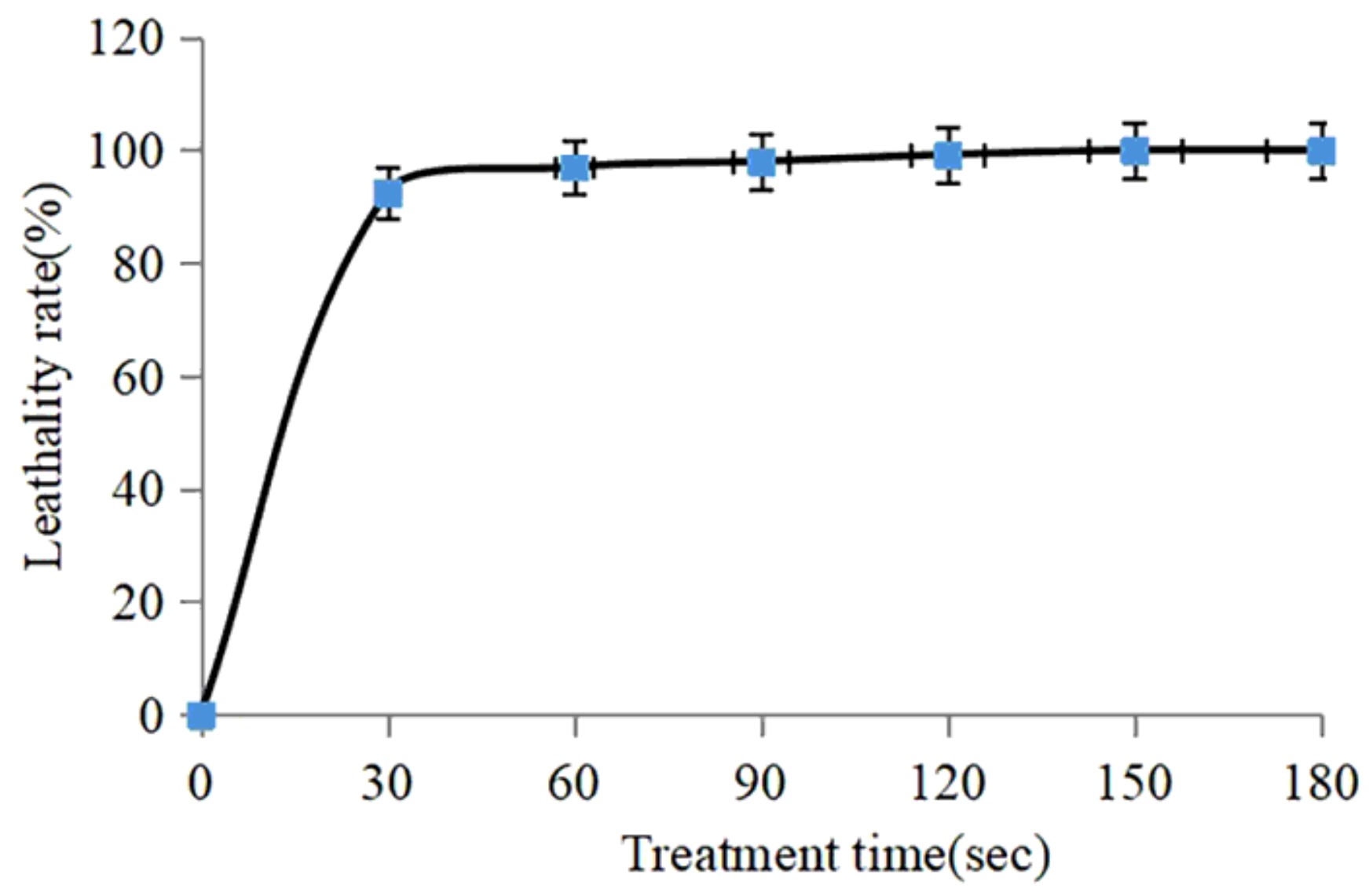

Figure 6

The lethality rate of formaldehyde degradation by ARTP

Figure 7

Fromaldehyde degradation by $P$. putia with the passage of incubation. (a) $\mathrm{OD}_{600}$ value of mutant strain WMZ120-5 on LB liquid medium with different formaldehyde concentrations of $0.5 \mathrm{~g} \mathrm{~L}^{-1}$ (open triangle, $\triangle$ ), $1.0 \mathrm{~g} \mathrm{~L}^{-1}$ (open circle, $\bullet$ ), $2.0 \mathrm{~g} \mathrm{~L}^{-1}$ (cross sign, $\mathrm{x}$ ), $3.0 \mathrm{~g} \mathrm{~L}^{-1}$ (filled circle, $), 4.0 \mathrm{~g} \mathrm{~L}^{-1}$ (filled square, $\square$ ), $5.0 \mathrm{~g} \mathrm{~L}^{-1}$ (filled triangle, $\mathbf{\Lambda}$ ), $6.0 \mathrm{~g} \mathrm{~L}^{-1}$ (filled diamond,囚), Control(open square, $\square$ ). (b) Formaldehyde concentration in the supernatants of the cultures mentioned above. An additional evaporation sample without cells was measured as a negative control containing $0.1 \mathrm{~g} \mathrm{~L}^{-1}$ formaldehyde (Control, open square, $\square$ ). Values were determined for two independent cultures, and mean values and arithmetic deviations from the mean are given. 


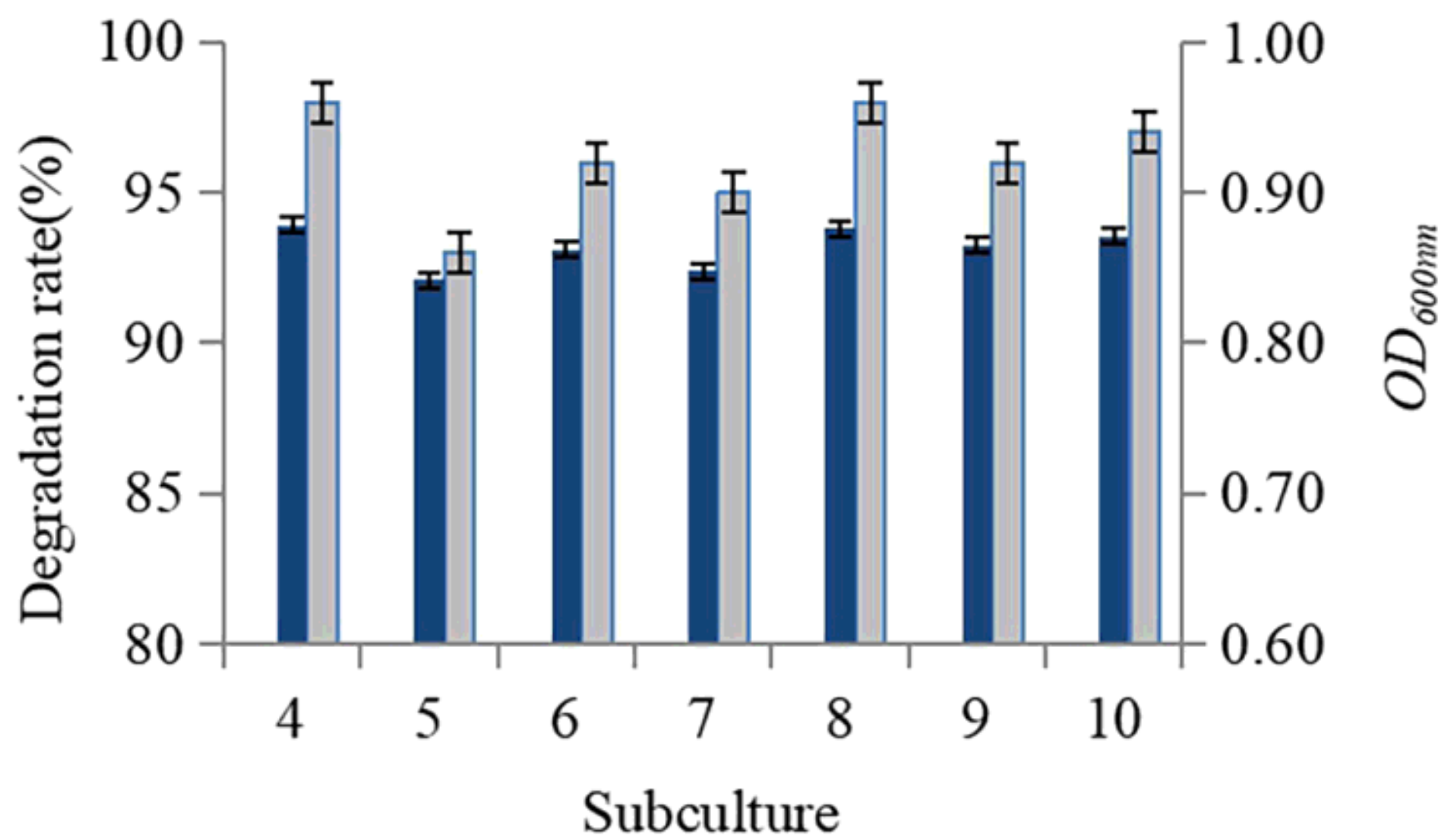

Figure 8

Cell density and formaldehyde degradation rate by mutant strain MWZ120-5 in LB medium containing formaldehyde at a concentration of $3.0 \mathrm{~g} \mathrm{~L}^{-1}$ with an $0 D 600 \mathrm{~nm}$ value (blue) and degradation rate (gray) within 96 hours. 